\title{
Maturação e desenvolvimento embrionário in vitro de oócitos bovinos após bloqueio da meiose com inibidores de MPF
}

\author{
In vitro maturation and embryo development of bovine oocytes after meiosis blockage with \\ MPF inhibitors
}

\author{
Mariana Groke MARQUES ${ }^{1}$; Marco Roberto Bourg de MELLO²; Liliam Mara Trevisan TAVARES; \\ Alessandra Corallo NICACIO ${ }^{4}$; Mayra Elena Ortiz D’Avila ASSUMPÇÃO ${ }^{5}$; José Antonio VISINTIN ${ }^{5}$ \\ ${ }^{1}$ EMBRAPA - Centro Nacional de Pesquisa de Suínos e Aves, Concórdia - SC, Brasil \\ ${ }^{2}$ Universidade Federal Rural do Rio de Janeiro, Seropédica - RJ, Brasil \\ ${ }^{3}$ Faculdade de Educação Ciências e Letras do Sertão Central da Universidade Estadual do Ceará, Itaperi - CE, Brasil \\ ${ }^{4}$ Universidade Estadual do Maranhão, São Luiz - MA, Brasil \\ ${ }^{5}$ Departamento de Reprodução Animal da Faculdade de Medicina Veterinária e Zootecnia da \\ Universidade de São Paulo, São Paulo - SP, Brasil
}

\begin{abstract}
Resumo
O objetivo deste estudo foi avaliar a maturação e o desenvolvimento embrionário após a fecundação in vitro de oócitos bovinos que tiveram a maturação bloqueada com Butirolactona I e Roscovitina em meio de pré-maturação suplementado com soro fetal bovino (SFB). Oócitos foram divididos em 4 grupos: Controle 0 hora, Controle (maturação por 24 horas), Butirolactona I (bloqueio da maturação com $150 \mu \mathrm{M}$ de Butirolactona I por 24 horas, seguido de 24 horas de maturação) e Roscovitina (bloqueio da maturação com $50 \mu \mathrm{M}$ de Roscovitina por 24 horas, seguido de 24 horas de maturação). Para avaliar a maturação nuclear, os oócitos foram fixados e corados em aceto orceína. Parte dos oócitos dos grupos Controle 24 horas, Roscovitina e Butirolactona I após o período de maturação, foi fecundado in vitro. O desenvolvimento embrionário foi avaliado pelos índices de clivagem (D3) e formação de blastocistos (D7). Oócitos do grupo Butirolactona I apresentaram índices de Vesícula Germinativa após o bloqueio e de Metáfase 2 após a maturação semelhantes ao dos grupos Controle 0 hora e Controle, respectivamente. Por outro lado, a Roscovitina apresentou menores índices de Vesícula Germinativa e Metáfase 2. Os grupos Controle e Butirolactona I apresentaram maiores índices de clivagens. O grupo Controle apresentou maior produção de blastocistos que o Roscovitina e não diferiu do grupo Butirolactona I. Conclui-se que a Butiroloactona I pode ser utilizada no sistema de pré-maturação em meio contendo SFB, pois apresentou resultados semelhantes ao do grupo Controle o mesmo não ocorrendo com a Roscovitina, que apresentou menores índices de maturação oocitária e de desenvolvimento embrionário.
\end{abstract}

Palavras-chave: Maturação oocitária. Butirolacnota I. Roscovitina. Produção in vitro de embriões.

\begin{abstract}
This study evaluated the bovine oocyte maturation and embryo development after in vitro fertilization. The maturation of the oocytes was blocked using Butyrolactone I and Roscovitine using pre-maturation medium supplemented with fetal calf serum (FCS). The ocytes were divided in four groups: Control 0 hour, Control (24 hours of maturation), Roscovitine (maturation blockage with 50mM Roscovitine during 24 hours followed by 24 hours of maturation), and Butyrolactone I (maturation blockage with $150 \mathrm{mM}$ Butyrolactone I during 24 hours followed by 24 hours of maturation). The oocytes were fixed and stained with aceto orcein to evaluate the nuclear maturation. After the maturation period, the remaining oocytes of the Control group, Roscovitine, and Butyrolactone I were fertilized in vitro. Embryo development was assessed by the cleavage rate (D3) and blastocysts formation (D7). The Butyrolactone I group had similar rates of germinal vesical stage oocytes during blockage, and Metaphase 2 after maturation, comparing to Control group at 0 hour and Control group, respectively. On the other hand, the Roscovitine group had lower rates of vesical stage oocytes during blockage, and Metaphase 2 after maturation comparing to Control groups. After in vitro fertilization, higher rates of cleavage were observed in Control and Butyrolactone I groups. For the blastocyst formation rate, the Control group showed better results than Roscovitine group. In summary, Butyrolactone I group had similar results to the Control group, and for this reason, is suitable for pre-maturation of bovine oocytes using FCS. In contrast, Roscovitine group had lower oocyte maturation and embryo development.
\end{abstract}

Keywords: Oocyte maturation. Butyroloactone I. Roscovitine. In vitro embryo production.

Correspondência para:

Mariana Groke Marques

EMBRAPA - Centro Nacional de Pesquisa de Suínos e Aves

BR 153, km 110, Tamandua - Concordia, Santa Catarina, Brasil
CEP: 89700-000

email: mariana.marques@cnpsa.embrapa.br

Recebido: $15 / 02 / 2011$

Aprovado: 09/11/2011 


\section{Introdução}

No ovário, os oócitos mamíferos permanecem em estádio inicial da divisão meiótica (vesícula germinativa - VG) até a liberação de gonadotrofina pré-ovulatória que estimula sua ativação ${ }^{1}$. Durante a fase final de maturação, os oócitos imaturos progridem de vesícula germinativa (prófase I - PI) para Metáfase 2 (M2), estádio em que permanecerão até a fecundação ou ativação da partenogênese ${ }^{2}$.

Anteriormente à maturação in vivo, ocorre um período de 4 a 5 dias de capacitação oocitária, que inclui a síntese e modificação de grande número de diferentes moléculas como RNAs e proteínas ${ }^{3}$. In vitro, os oócitos retomam a meiose imediatamente depois da sua retirada do folículo, significando que muitos oócitos em M2 não sofreram adequadamente o processo de capacitação, desta forma não têm a mesma competência para se desenvolver em comparação aos oócitos maturados in vivo ${ }^{3}$.

Os eventos moleculares que ocorrem durante o período final da maturação oocitária não são conhecidos, mas suspeita-se que os transcritos e proteínas, que são armazenados de forma estável durante este período, terão importante função durante o início do desenvolvimento embrionário, quando ocorre a quiescência do genoma do embrião ${ }^{4}$.

Assim, Kubelka et al. ${ }^{5}$ notaram o efeito da inibição reversível da quebra da VG (QVG) e evidenciaram este fato pelo desenvolvimento do sistema de cultura em duas etapas para proporcionar tempo suficiente para os oócitos desenvolverem competência meiótica completa, resultando em oócitos de melhor qualidade para atingir a maturação citoplasmática com sucesso.

A progressão exata e ordenada do ciclo celular é rigidamente controlada pela sequência de formação, ativação e inativação de uma série de quinases reguladoras. A chave para a regulação do ciclo celular são as quinases dependentes de ciclina (CDKs) ${ }^{6}$. Existem dois pontos de checagem no ciclo celular, a transição de G2/M e de metáfase/anáfase, sendo estes essenciais para manutenção da ordem dos eventos no ciclo celular?

Uma forma de bloqueio da QVG é a inibição do fator promotor de maturação (MPF). O MPF é um complexo proteico de alto peso molecular com atividade de proteína quinase, presente tanto na meiose quanto na mitose $^{5}$. Este complexo consiste de duas subunidades principais, uma quinase dependente de ciclina e uma ciclina, sendo que a quinase precisa estar associada à ciclina para se tornar ativa, na forma de $\mathrm{MPF}^{8}$.

Experimentos provaram que a Butirolactona I é um inibidor seletivo de quinases dependentes de ciclina, por inibir tanto a cdk2 quanto a cdc2 quinases e bloquear o ciclo celular em G1/S e G2/M. Além disso, em oócitos de mamíferos (ratos, suínos e bovinos), a ação da Butirolactona I resulta na inibição da quebra da Vesícula Germinativa9 . Pavlok et al. ${ }^{10}$ mostraram que oócitos cultivados na presença do Butirolactona I continuam sintetizando rRNA, sendo a síntese diminuída apenas com a compactação da cromatina.

Derivados da purina são inibidores mais específicos do MPF, sendo indicados e usados com sucesso para prevenir a divisão celular. Estudos indicam que a ação é localizada no ATP ligado a quinase cdc2 e isso impede a liberação do ATP necessário para ativação da fosforilação da molécula. A Roscovitina, representante do grupo dos derivados da purina, é um potente inibidor de ativação da quinase que forma o MPF, sendo usado para manter oócitos bovinos em estádio de VG, quando em cultura por 24 horas 4 .

Com o descrito nesta introdução, vários estudos foram realizados com a Butirolactona I e com a Roscovitina na maturação de oócitos bovinos. No entanto, apenas os estudos Adona e Leal ${ }^{11}$, no qual foi utilizada a albumina sérica bovina (BSA) no meio de pré-maturação, realizaram a comparação do efeito da pré-maturação com estas drogas no desenvolvimento embrionário pós-fecundação in vitro, havendo assim a necessidade de estudos que realizem esta compara- 
ção em outras condições de maturação, fecundação e cultivo in vitro.

A suplementação proteica durante a maturação in vitro (MIV) podem ter profundos efeitos sobre os índices de produção e desenvolvimento embrionário, refletindo nos índices de mórula e blastocisto ${ }^{12}$. Além disso, é sabido que alterações da suplementação do meio de pré-maturação podem adicionar fatores que aumentem a produção de embriões in vitro ${ }^{13}$.

Resultados obtidos por Leibfried-rutledge, Critser e First ${ }^{15}$ demonstraram que o SFB foi superior em comparação a albumina sérica bovina (BSA) para MIV de hamster e bovinos, quando utilizado meio TCM199 para a maturação. Ainda, Saúirkaya et al. ${ }^{14}$ demonstraram que a suplementação com SFB durante a maturação oocitária produz embriões com número menor de células em apoptose após a fecundação in vitro.

Desta forma, o objetivo deste estudo foi avaliar os índices de maturação e de produção de embriões, a partir de oócitos bovinos após bloqueio da meiose por 24 horas pelos inibidores Butirolactona I e Roscovitina em meio de pré-maturação e de maturação contendo soro fetal bovino.

\section{Material e Método}

Salvo quando descrito, todos os reagentes foram adquiridos da Sigma (Sigma-Aldrich Corp, St. Louis, MO, EUA).

Experimento 1: Avaliação da maturação, bloqueio e retomada da maturação dos oócitos

Os ovários foram obtidos em abatedouro e mantidos a $30{ }^{\circ} \mathrm{C}$, em solução salina com antibiótico, durante o transporte para o laboratório (aproximadamente 3 horas). Os complexos cumulus oócitos (CCOs) foram aspirados de folículos medindo 2-8 $\mathrm{mm}$ de diâmetro, utilizando seringa acoplada a agulha $21-\mathrm{G}$. Os CCOs foram avaliados morfologicamente e somente oócitos que apresentaram três ou mais camadas de células do cumulus compactas e ooplasma homogêneo (grau 1), seguindo a classificação descrita por Konishi et al. ${ }^{18}$, foram selecionados e divididos em quatro grupos:

- Controle 0 hora: oócitos fixados e corados logo após a seleção;

- Controle: maturação por 24 horas em meio de maturação [TCM 199 Gibco BRL (Grand Island, NY, EUA) acrescido de $10 \%$ de soro fetal bovino, com 0,5mg/mL FSH (Folltropin; Vetrepharm, Belleville, Ontário, Canadá), $50 \mathrm{mg} / \mathrm{mL}$ de LH (Chorulon, Intervet, Boxmeer, Holanda), $1 \mathrm{mg} / \mathrm{mL}$ de estradiol (Sigma, St. Louis, MO, EUA), $22 \mathrm{mg} / \mathrm{mL}$ de piruvato e $50 \mathrm{mg} / \mathrm{mL}$ de gentamicina];

- Roscovitina: bloqueio da maturação por 24 horas em meio de maturação contendo $50 \mu \mathrm{M}$ de Roscovitina, seguido de 24 horas em meio de maturação sem bloqueador (maturação);

- Butirolactona I: bloqueio da maturação por 24 horas em meio de maturação contendo $150 \mu \mathrm{M}$ de Butirolactona I (Biomol Resarch Laboratories, Plymouth Meeting, PA, EUA) seguido de 24 horas em meio de maturação sem bloqueador (maturação).

Tanto o bloqueio quanto à maturação oocitária foram realizadas em gotas de $90 \mu \mathrm{L}$ de meio cobertas com óleo mineral, com 20 a 30 oócitos, em estufa a $38,5^{\circ} \mathrm{C}, 5 \%$ de $\mathrm{CO}_{2}$ em ar e alta umidade. O tempo transcorrido entre a retirada dos oócitos dos folículos e sua introdução no meio de maturação foi de aproximadamente 2 horas.

Para avaliar o estágio de maturação nuclear, os oócitos do grupo Controle 0 hora, metade do grupo Controle 24 horas, e metade dos grupos Roscovitina a Butirolactona I após as 24 horas de bloqueio e após 24 horas em meio de maturação, tiveram as células do cumulus retiradas mecanicamente, sendo os oócitos colocados entre lâmina e lamínula, fixados por 24 horas em etanol e ácido acético glacial (3:1) e corados com solução de orceína (1g de orceína, $20 \mathrm{ml}$ de ácido acético e $56 \mathrm{ml}$ de água destilada) por 10 minutos 
para observação do estágio de maturação nuclear, em microscópio de contraste de interferência diferencial (aumento de 1000X).

Foram realizadas oito repetições, distribuídas nos quatro grupos experimentais (95 - 115 oócitos por grupo).

Experimento 2 - Efeito do bloqueio da maturação no desenvolvimento embrionário

Após o período de maturação, o restante dos oócitos dos grupos Controle 24 horas, Roscovitina e Butirolactona I foi fecundado in vitro.

Para a fecundação in vitro foi utilizado o protocolo descrito por Parrish et al. ${ }^{19}$ modificado. O sêmen foi descongelado e centrifugado em gradiente de Percoll (45 e 90\%), por 30 minutos a 700 g. O sedimento foi ressuspendido em meio de fecundação TALP (99,0 $\mathrm{mM}$ de $\mathrm{NaCl}, 3,1 \mathrm{mM}$ de $\mathrm{KCl}, 25,0 \mathrm{mM}$ de $\mathrm{NaHCO}_{3}$ 0,35 mM de $\mathrm{NaH}_{2} \mathrm{PO}_{4}, 2,0 \mathrm{mM}$ de $\mathrm{CaCl}_{2}, 1,1 \mathrm{mM}$ de $\mathrm{MgCl}_{2} 6 \mathrm{H}_{2} \mathrm{O}, 21,6 \mathrm{mM}$ de $\mathrm{DL}$ ácido lático, 1,0 mM de piruvato de sódio, $3,0 \mathrm{mg} / \mathrm{mL}$ de BSA-V e $100 \mathrm{mg} /$ $\mathrm{mL}$ penicilina $\mathrm{G}$ ). Os oócitos após o período de maturação foram lavados e incubados em meio de fecundação, onde foram acrescentados os espermatozoides, na concentração de $1 \times 10^{6}$ espermatozoides $/ \mathrm{mL}$. As placas de Petri foram mantidas em estufa com 5\% de $\mathrm{CO}_{2} \mathrm{em}$ ar, $39^{\circ} \mathrm{C}$ e alta umidade. $\mathrm{O}$ dia da fecundação foi considerado como dia zero (D0).

Após 18 horas da fecundação, grupos de com 20 a 30 prováveis zigotos, tiveram as células do cumulus removidas mecanicamente e foram cultivados em meio TCM 199 acrescido de $10 \%$ de soro fetal bovino e $50 \mathrm{mg} / \mathrm{mL}$ de gentamicina em cocultivo em monocamada de células da granulosa. O cultivo embrionário foi realizado em gotas de $90 \mu \mathrm{L}$ cobertas com óleo mineral em estufa com $5 \%$ de $\mathrm{CO} 2 \mathrm{em}$ ar, $39^{\circ} \mathrm{C}$ e alta umidade. Após 48 horas de cultivo foram acrescidos $90 \mu \mathrm{L}$ do meio de cultivo às microgotas (feeding). Os embriões foram avaliados quanto aos índices de clivagem às 72 horas de cultivo e de blastocisto no sétimo dia de desenvolvimento.
Foram realizadas oito repetições, nos três grupos experimentais: Controle, Roscovitina e Butirolactona I (174 - 191 oócitos por grupo). Os índices de clivagem foram calculados pela divisão do número de zigotos pelo número total de oócitos que foram fecundados. Os índices de blastocistos foram calculados pela divisão do número de embriões que alcançaram o estágio de blastocisto até o sétimo dia de cultivo pelo número total de oócitos que foram fecundados.

\section{Análise estatística}

Os dados foram testados quanto à normalidade dos resíduos e homogeneidade das variâncias pelo aplicativo Guided Data Analisys. As variáveis foram submetidas ao PROC MIXED dos recursos do pacote estatístico SAS, versão 9.1.3 para Windows. Foi utilizado o LSMEANS (média dos quadrados mínimos) para obtenção das médias ajustadas dos tratamentos, com comparações utilizando-se o Teste de Tukey.

$\mathrm{O}$ nível de significância utilizado para rejeitar $\mathrm{H0}$ foi de $5 \%$, isto é, para nível de significância menor que 0,05 considerou-se que ocorreram diferenças entre a variável classificatória (Roscovitina e Butirolactona I) para determinada variável resposta (estagio de maturação nuclear, clivagem e blastocistos).

\section{Resultados}

Experimento 1: Avaliação da maturação, bloqueio e retomada da maturação dos oócitos

A figura 1 mostra os diferentes estágios de maturação de oócitos corados com orceína.

Quando comparados os estágios de maturação dos oócitos após a seleção (grupo Controle 0 hora) com os grupos que foram submetidos ao bloqueio por 24 horas, pôde-se observar que os oócitos que foram bloqueados com Butirolactona I apresentaram índices semelhantes de oócitos em VG e QVG em relação ao grupo Controle 0 hora. $\mathrm{O}$ mesmo não ocorreu com o grupo de oócitos bloqueados com Roscovitina, que apresentou menores índices de VG e QVG e maiores 


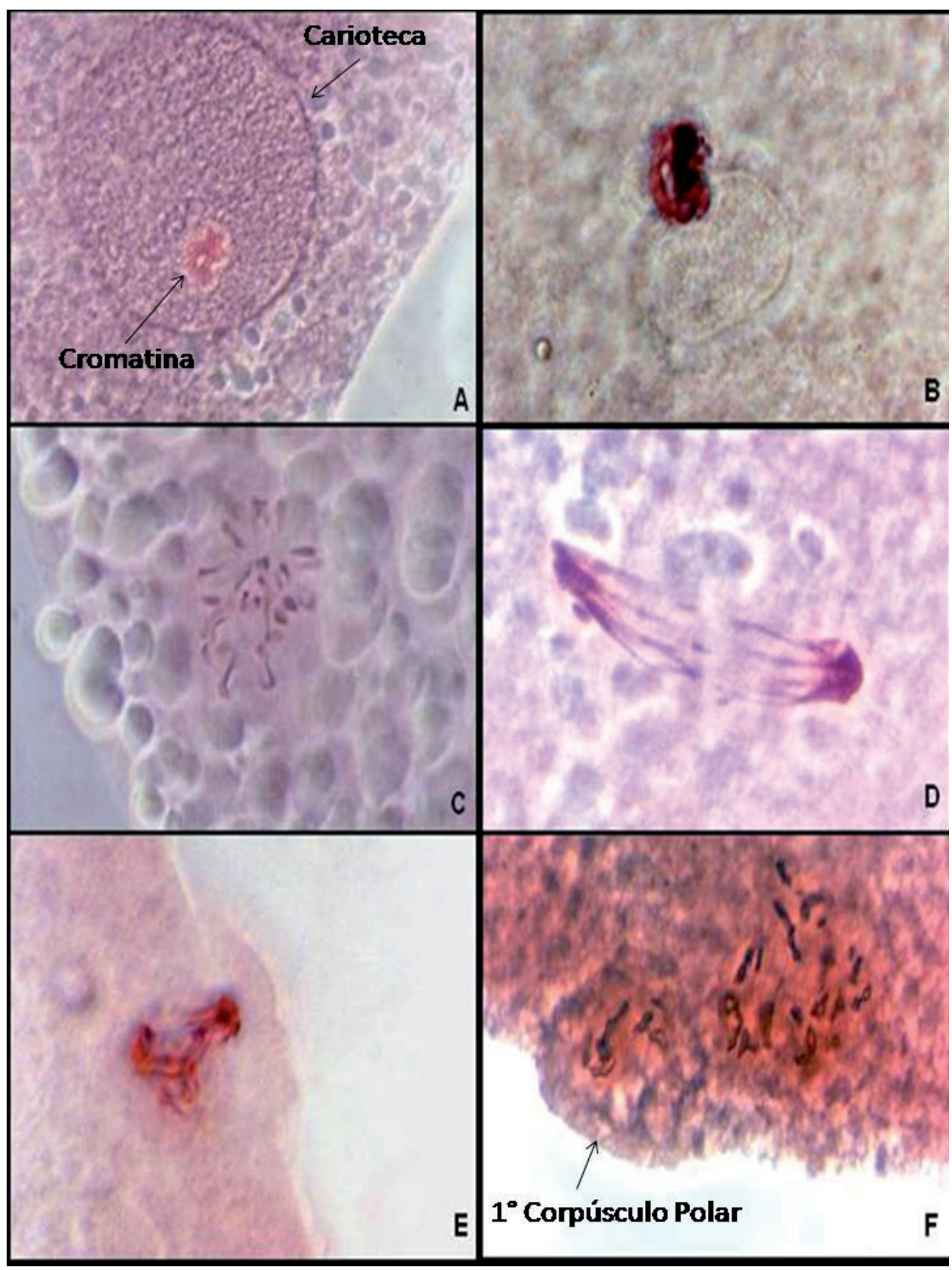

Figura 1 - Oócitos bovinos em diferentes estágios de maturação nuclear. Vesícula Germinativa (A), Quebra de Vesícula Germinativa (B), Metáfase 1 (C), Anáfase 1 (D), Telófase 1 (E) e Metáfase 2 e expulsão do primeiro Corpúsculo Polar (F). Coloração: Orceína. Aumento 1000X

índices de M1 que os grupos Controle e Butirolactona I (Figura 2).

Após 24 horas de maturação, foi observado que apenas o grupo previamente bloqueado com Butirolactona I apresentou índice de oócitos em Metáfase 2 (M2) semelhante ao grupo Controle, tendo o grupo previamente bloqueado com Roscovitina apresentado resultados de oócitos maturos inferiores a estes dois grupos. Além disso, foi observada tendência a maior ocorrência de oócitos em Metáfase 1 (M1) no grupo Roscovitina que no grupo Controle (Figura 3). Morfologicamente, nenhuma alteração que sugerisse efeito tóxico das drogas foi verificada. 


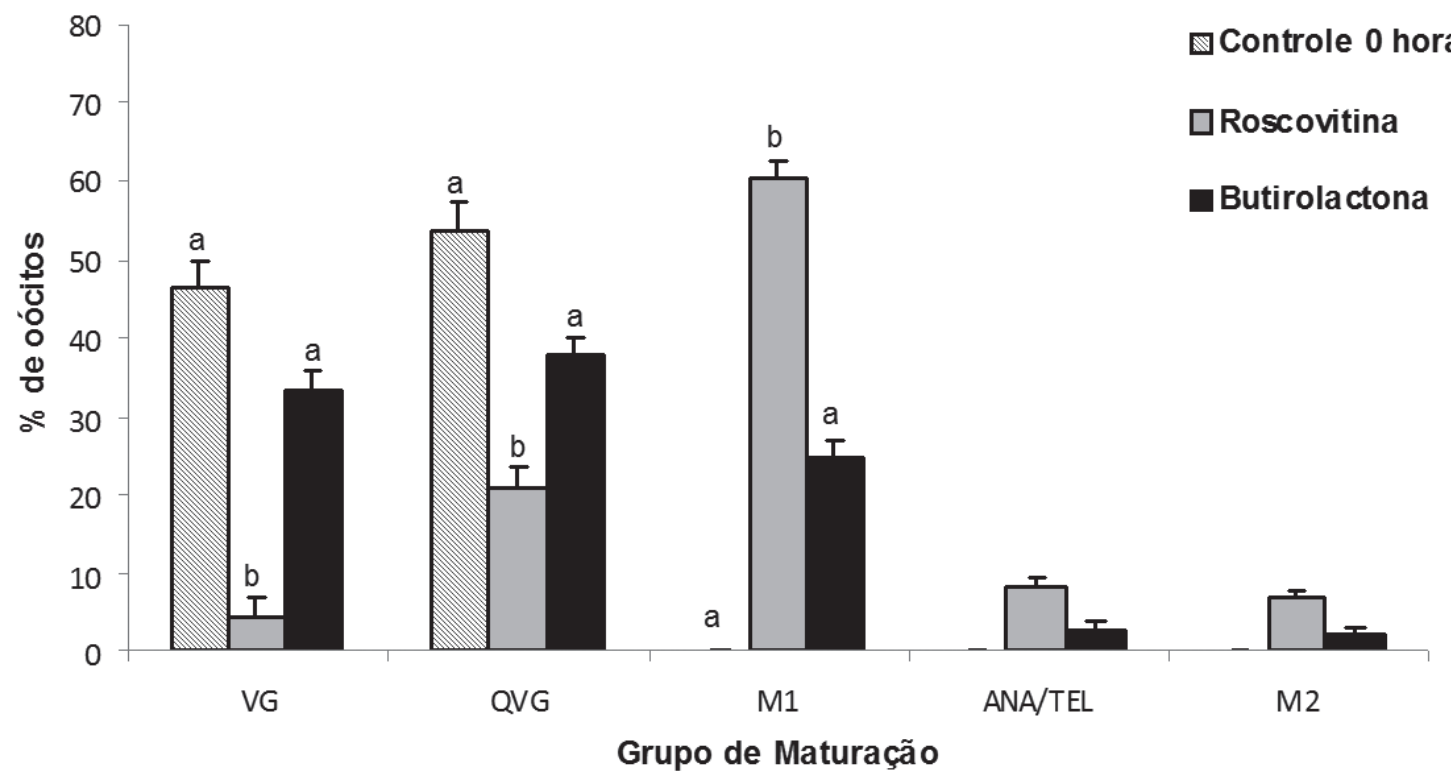

Figura 2 - Porcentagem de oócitos nos diferentes estágios de maturação nuclear dos grupos: Controle 0 hora (oócitos fixados e corados logo após a seleção), bloqueados por 24 horas com Roscovitina ou bloqueados por 24 horas Butirolactona I. Letras diferentes sobrescritas em cada barra dentro de cada estágio de maturação representam diferença significativa $(\mathrm{P}<0,05)$. Os dados representam as médias dos quadrados mínimos $\pm \mathrm{EP}$

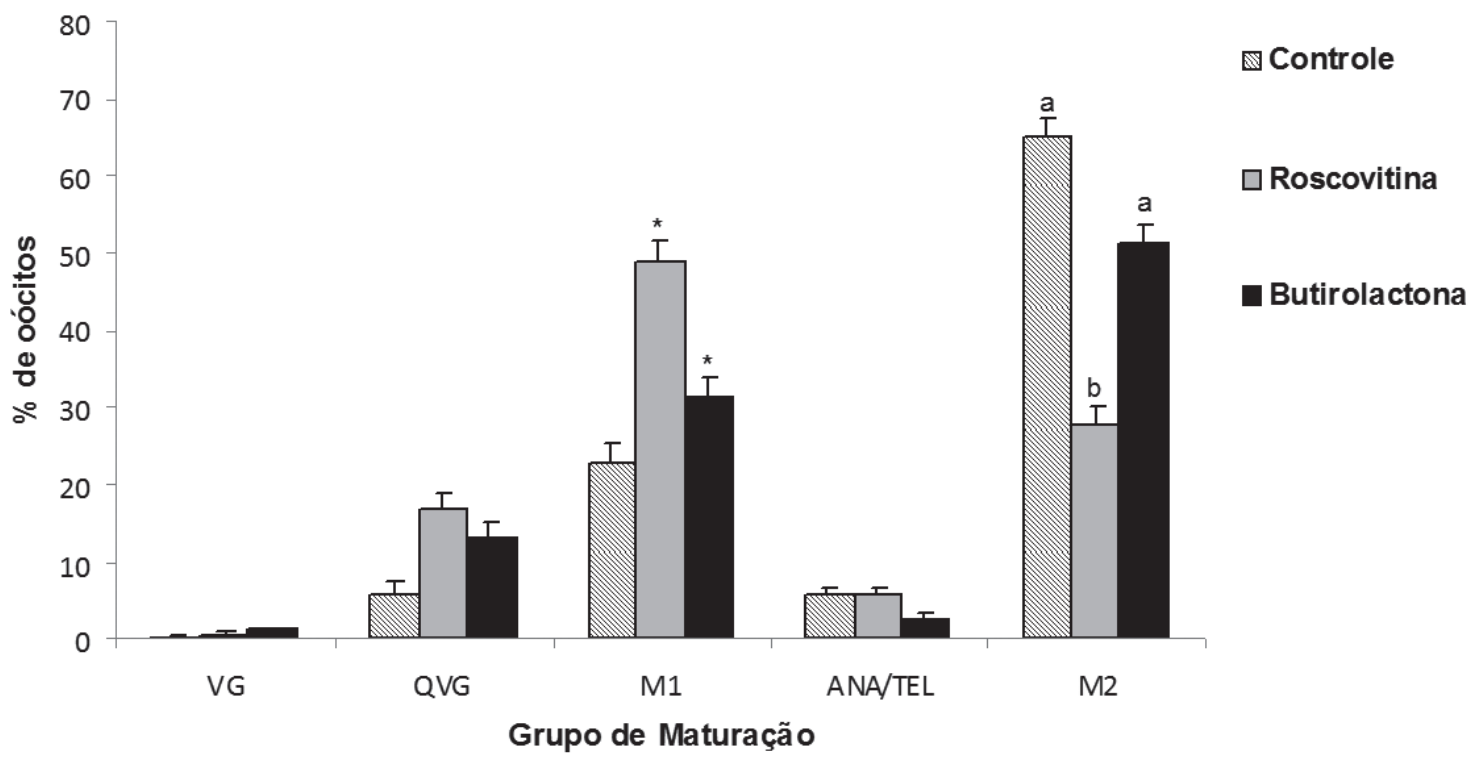

Figura 3 - Porcentagem de oócitos nos diferentes estágios de maturação nuclear dos grupos: Controle (após 24 horas de maturação in vitro), maturados in vitro por 24 horas após bloqueio da maturação com Roscovotina ou maturados in vitro por 24 horas após bloqueio da maturação com Butirolactona I. Letras diferentes sobrescritas em cada barra dentro de cada estágio de maturação representam diferença significativa $(\mathrm{P}<0,05) .{ }^{*}$ sobrescritos em cada barra dentro de cada estágio de maturação representam tendência à diferença significativa $(0,05<\mathrm{P}<0,10)$. Os dados representam as médias dos quadrados mínimos $\pm \mathrm{EP}$ 
Experimento 2 - Efeito do bloqueio da maturação no desenvolvimento embrionário.

Após a realização da fecundação in vitro dos oócitos, foram observados maiores índices de clivagens nos grupos Controle e previamente bloqueado com Butirolactona I que no grupo Roscovitina. Para os índices de formação de blastocistos, o grupo Controle apresentou melhores resultados que o Roscovina, não diferindo do grupo Butirolactona 1. Houve tendência de diferença entre os grupos Roscovitina e Butirolactona I (Figura 4).

\section{Discussão}

Visando a melhoria dos índices de maturação, tanto nuclear quanto citoplasmática, assim como de oócitos aptos à fecundação, foram utilizados sistemas de maturação em duas etapas (bloqueio e desbloqueio da maturação) para proporcionar tempo suficiente para os oócitos desenvolverem competência meiótica completa.
Em seus estudos, Kubelka et al. ${ }^{5}$ concluíram que o tratamento com Butirolactona I é um método eficiente para aumentar os índices de meiose e do desenvolvimento de oócitos bovinos após serem retirados do tecido ovariano.

Vários estudos ${ }^{20,21}$ utilizaram na espécie bovina a concentração de $100 \mu \mathrm{M}$ de Butirolactona I, no entanto nestes estudos foi utilizado BSA como suplementação do meio de pré-maturação. Como neste estudo foi utilizado meio de maturação suplementado com SFB, optou-se pela utilização de $150 \mu \mathrm{M}$ de Butirolactona I, já que Kubelka et al. ${ }^{5}$ relataram que o uso de SFB no meio de maturação, resulta em perda parcial da capacidade de bloqueio devido à ligação de componentes do soro à Butirolactona I, tendo sido obtidos melhores resultados concentrações maiores da droga para meios com SFB.

Mermillod et al. ${ }^{4}$ em estudos com Roscovitina, inferiram que o sistema de cultura de pré-maturação é

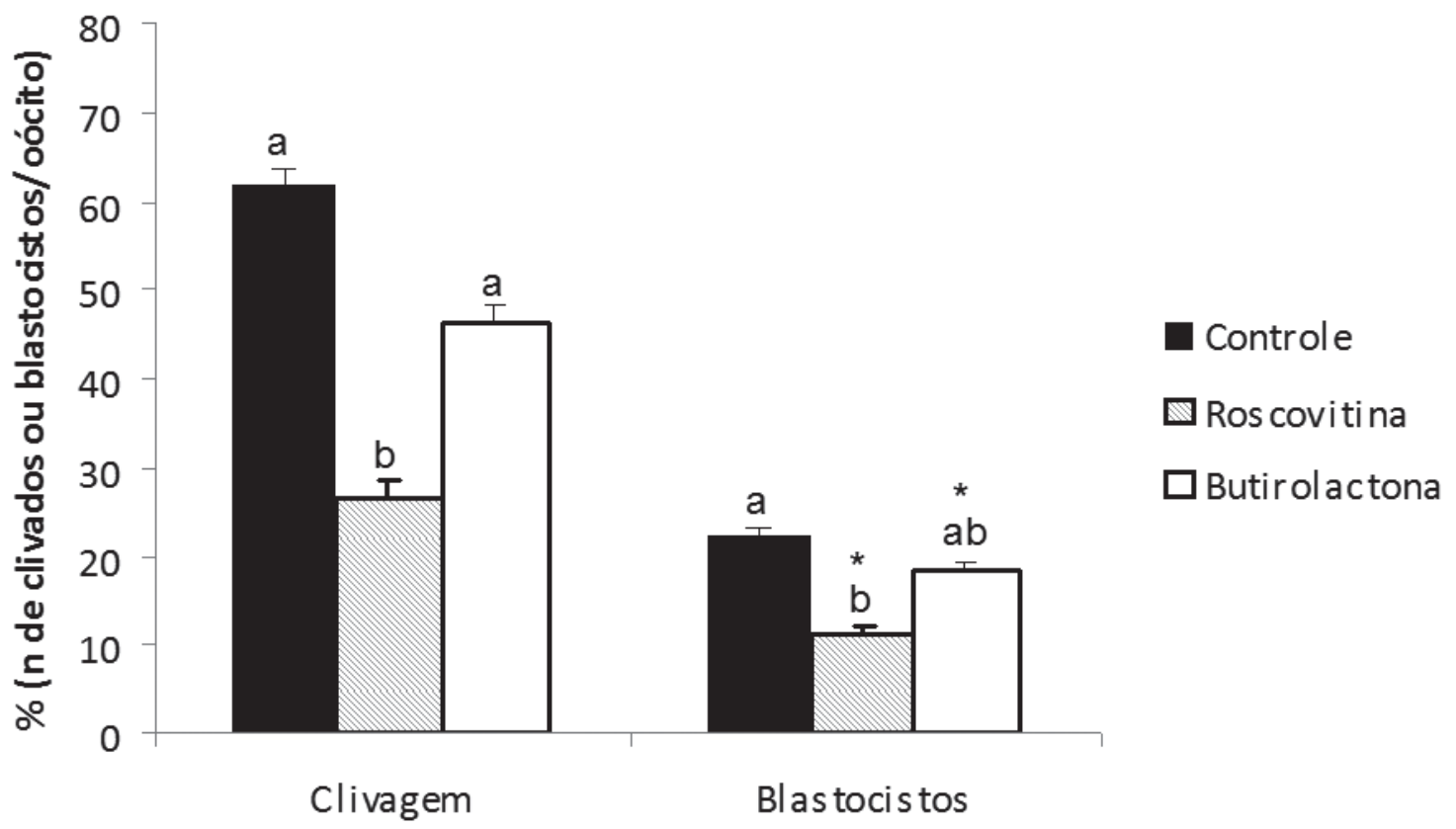

Figura 4 - Porcentagem de zigotos clivados (D3) e de embriões que atingiram o estágio de blastocistos (D7) após a fecundação in vitro de oócitos provenientes dos grupos Controle (após 24 horas de maturação in vitro) e maturados in vitro por 24 horas após bloqueio da maturação com Roscovotina ou Butirolactona I. Letras diferentes sobrescritas em cada barra dentro de cada estágio de desenvolvimento representam diferença significativa $(\mathrm{P}<0,05)$. ${ }^{\star}$ sobrescritos em cada barra representam tendência à diferença significativa $(0,05<\mathrm{P}<0,10)$. Os dados representam as médias dos quadrados mínimos $\pm \mathrm{EP}$ 
eficiente quando aplicado em oócitos com baixa competência de desenvolvimento (oócitos oriundos de folículos de tamanho reduzido), visando reproduzir as etapas de diferenciação oocitária que normalmente ocorrem durante a foliculogênese.

Ao contrário do previsto, o índice de oócitos em QVG encontrado no grupo Controle 0 hora foi bastante alto quando comparado com a literatura. Vários grupos de pesquisa, entre eles, Dode e Adona ${ }^{22}$, relatam índices de $100 \%$ de VG no momento considerado 0 hora. No entanto, não relatam qual foi o tempo de transporte dos ovários e o tempo de manipulação do material. Barretto et al..$^{23}$ não revelaram o tempo de aquisição dos oócitos, mas ao utilizar oócitos provenientes de folículos de 2 a $8 \mathrm{~mm}$, obtiveram índices de $79.90 \pm 8.29$ oócitos em VG à 0 hora, resultados mais próximos dos demostrados aqui.

Em outros estudos, Adona et al..$^{24}$ relatam $100 \%$ de VG à 0 hora, sendo utilizado tempo de transporte de 2 horas e 1 - 1,5 horas da aspiração do oócito até este chegar ao meio de maturação, e além disso foram utilizados oócitos de folículos de 2 a $6 \mathrm{~mm}$.

Acreditamos que o tempo prolongado entre o abate e seleção dos oócitos, principalmente pelo grande período de transporte, a utilização de folículos de 2 a $8 \mathrm{~mm}$, aliados ao fato da ausência de bloqueador no meio em que foi realizada a procura e seleção dos oócitos tenham colaborado para os altos índices de QVG à 0 hora.

Apesar disso, a Butirolactona I apresentou índices de VG e QVG igual ao do Controle 0 hora, mostrando ser eficiente em manter os oócitos na mesma fase do ciclo celular em que estavam antes da maturação em duas etapas (bloqueio e desbloqueio da maturação).

No grupo de oócitos bloqueados com Roscovitina, os resultados não foram satisfatórios, pois o índice de VG foi menor do que o grupo Controle 0 hora e da Butirolactona I. O índice de Metáfase 1 deste grupo foi maior do que o grupo Controle 0 hora do Butirolactona I. Isso indica que os oócitos não bloqueados em VG foram bloqueados no segundo ponto de checagem do ciclo celular, isto é em Metáfase 1(M1).

Após o desbloqueio, os oócitos do grupo Roscovitina apresentaram índices de Metáfase 2 (M2) menores do que os outros grupos Controle e do grupo Butirolactona I, podendo este fato ser confirmado pelo alto número de oócitos que se mantiveram em M1 após o bloqueio. Demonstrando que os oócitos bloqueados com Roscovitina não tiveram a mesma eficiência em retomar a maturação que o grupo bloqueado com Butirolactona I.

Albarracín et al. ${ }^{26}$ demonstraram que o bloqueio da meiose por 24 horas com Roscovitina não comprometeria o potencial de desenvolvimento dos oócitos já que alterações na configuração da placa metafásica e de citoesqueleto seriam reversíveis após a remoção da droga.

No entanto Faerge et al. ${ }^{25}$ ao avaliarem, por microscopia eletrônica, oócitos que tiveram a maturação bloqueada com Roscovitina por oito horas, mostraram que estes apresentam ondulações na membrana nuclear e moderada condensação na cromatina o que não foi verificado em mesma intensidade quando utilizada a Butirolactona I pelo mesmo período. Quando utilizada por períodos maiores de tempo, como o relatado aqui (24 horas), as alterações decorrentes do uso da Roscovitina podem ter causado danos aos oócitos, levando à não retomada da meiose e assim, menores índices de MII após a maturação.

Após a fecundação in vitro, foi observado que ambos os tratamentos utilizados não obtiveram melhores resultados que o grupo Controle. No entanto, os resultados aqui apresentados estão de acordo com o estudo de Adona et al. ${ }^{13}$, no qual oócitos pré-maturados com Butirolactona I por 24 horas apresentaram resultados semelhantes ao do grupo Controle na produção de blastocistos. Estes resultados indicam o possível uso deste bloqueador no transporte de oócitos por longas distâncias, evitando, desta forma, o envelhecimento dos mesmos, pois mantém a viabilidade oocitária por 
até 24 horas, sendo isto também possível em meio de pré-maturação suplementado com SFB.

O grupo Roscovitina não se mostrou adequado para oócitos aspirados de folículos de tamanhos variados (diâmetro aproximado de 2 a $8 \mathrm{~mm}$ ), possivelmente pelo menor grau de retomada da meiose e assim menores índices de fecundação e desenvolvimento embrionário.

Foi verificado também que estudos que utilizaram meio de pré-maturação contendo SFB e os oócitos bloqueados com Roscovitina apresentaram resultados baixos na produção de blastocistos, como demostrado nos estudos de Albarracín et al. ${ }^{26}$ e no presente estudo. No entanto, estudos que utilizaram meio de pré-maturação suplementado com BSA ${ }^{11,24}$ apresentaram melhores resultados.

Os fatores responsáveis por estes resultados ainda não são claros, embora fatores que podem contribuir seriam a fonte e o lote da Roscovitina utilizada, a fonte de ovários, o sistema IVM e/ou o procedimento utilizado para avaliar os resultados ${ }^{26}$. Além de uma possível interação entre o SFB e a Roscovitina.

Pode ter colaborado ainda para os resultados obtidos aqui o fato de terem sido utilizadas gonadotrofinas

\section{Referências}

1. RICHARD, F. J. SIRARD, M. A. Effects of follicular cells on oocyte maturation. II. Theca cell inhibition of bovine oocyte maturation in vitro. Biology of Reproduction, v. 54, n. 1, p. 22-28, 1996.

2.LONERGAN, P.; DINNYES, A.; FAIR, T.; YANG, X. BOLAND, M. Bovine Oocyte and Embryo Development Following Meiotic Inhibition With Butyrolactone I. Molecular Reproduction and Development, v. 57, n. 1, p. 204-209, 2000.

3. AVERY, B.; FAERGE, I.; HOLM, P. Confocal Microscopy of bovine opu oocytes and Roscovitine treated abattoir oocytes with emphasis on Mitochondria distribution and nuclear stage. Theriogenology, v. 57, n. 1, p. 711, 2002.

4. MERMILLOD, P.; TOMANEK, M.; MARCHAL, R.; MEIJER, L. High Developmental Competence of Cattle Oocytes Maintained at the Germinal Vesicle Stage for 24 Hours in Culture by Specific Inhibition of MPF Kinase Activity. Molecular Reproduction and Development, v. 1, n. 55, p. 89-95, 2000.

5. KUBELKA, M.; MOTLÍK, J.; SCHULTZ, R. M.; PAVLOK, A. Butyrolactone I Reversibly Inhibits Meiotic Maturation of Bovine Oocytes, Without Influencing Chromossome Condensation Activity. Biology of Reproduction, v. 62, n. 2, p. 292-302, 2000. durante o bloqueio. A utilização de meio de maturação idêntico na pré-maturação e na maturação oocitária visava uma maior estimulação dos oócitos pelas gonadotrofinas. Fisiologicamente, o COCs entra em contato com FSH, estrógeno e quantidades crescente de $\mathrm{LH}$, até o momento do pico de $\mathrm{LH}$ que descadeia a retomada da maturação oócitaria. No entanto, em um estudo recente, Barretto et al. ${ }^{27}$ demonstraram que o uso de substâncias estimulatórias como as gonadotrofinas e o estradiol não são suplementos adequados para o meio no qual será realizado o bloqueio meiótico, já que na sua presença o bloqueio por mais de oito horas não foi mantido adquadamente.

Desta forma, pode-se concluir que a Butirolactona I pode ser utilizada no sistema de pré-maturação em meio contendo SFB, pois apresentou resultados semelhantes ao do grupo Controle; o mesmo não ocorrendo com o grupo pré-maturado na presença de Roscovitina, que apresentou índices menores de maturação oocitária e de desenvolvimento embrionário.

\section{Agradecimentos}

Agradecemos à Fundação de Amparo a Pesquisa do Estado de São Paulo (FAPESP) pelo auxílio financeiro.

6. SCHUTTE, B.; NIELAND, L.; ENGELAND, M. V.; HENFLING, E. R.; MEIJER, L; RAMAEKERS, F. C. S. The effect of cyclindependent kinase inhibitor olomoucine on cell cycle kinetics. Experimental Cell Research, v. 236, n. 1, p. 4-15, 1997.

7.MOTLIK, J.; PAVLOK, A.; KUBELKA, M.; KALOUS, J.; KALAB, P. Interplay between cdc2 kinase and MAP kinase pathway during maturation of mammalian oocytes. Theriogenology, v. 49, n. 2, p. 461-469, 1998.

8. ALBERTS, B.; BRAY, D.; LEWIS J.; RAFF, M.; ROBERTS, K.; WATSON, D. J. Molecular biology of the cell. 3. ed. New York: Garland Publishing, 1994.

9. MOTLIK, J.; KUBELKA, M. Activation of mammalian oocytes as an essential step for nem biotechniques. Arquivo da Faculdade de Veterinária UFRGS, v. 27, n. 1, p. 89-99, 1999.

10.PAVLOK, A.; KANKA, J.; MOTLÍK, J.; VODICKA, P. Culture of bovine oocytes in meiosis-inhibiting medium with butylactone I: RNA synthesis, nucleolar morphology and meiotic competence. Animal Reproduction Science, v. 64, n. $1-2$, p. 1-11, 2000.

11.ADONA, P. R.; LEAL, C. L. V. Meiotic inhibition with different cyclin-dependent kinase inhibitors in bovine oocytes and its 
effects on maturation and embryo development. Zygote, v. 12 , n. 3, p. 197-204, 2004.

12.ALI, A.; SIRARD, M. A. Effect of the absence or presence of various protein supplements on further development of bovine oocytes during in vitro maturation. Biology of Reproduction, v. 66, n. 4 , p. $901-905,2002$.

13.ADONA, P.; DE BEM, T.; MESQUITA, L.; ROCHETTI, R.; LEAL, C. Embryonic development and gene expression in oocytes cultured in vitro in supplemented pre-maturation and maturation media. Reproduction Domestic Animal, v. 46, n. 1, p. 31-38, 2011.

14.SAÚIRKAYA, H.; YAÚMUR, M.; NUR, Z.; SOYLU, M. K. Replacement of fetal calf serum with synthetic serum substitute in the in vitro maturation medium: effects on maturation, fertilization and subsequent development of cattle oocytes in vitro. Turkish Journal Veterinary and Animal Science, v. 28, n. 1, p. 779-784, 2004.

15.LEIBFRIED-RUTLEDGE, M. L.; CRITSER, E. S.; FIRST, N. L. Effects of fetal calf serum and bovine serum albumin on in vitro maturation and fertilization of bovine and hamster cumulus-oocyte complexes. Biology of Reproduction, v. 35, n. 4 , p. $850-857,1986$.

16.SAGIRKAYA, H.; MISIRLIOGLU, M.; KAYAC, A.; FIRST, N. L.; PARRISH, J. J.; MEMILI, E. Developmental potential of bovine oocytes cultured in different maturation and culture conditions. Animal Reproduction Science, v. 101, n. 3/4, p. 225-240, 2007.

17.MINGOTI, G.Z.; CASTRO, V.S. D.C.; MÉO, S.C.;BARRETTO, L. S. S.; GARCIA, J. M. The effects of macromolecular and serum supplements and oxygen tension during bovine in vitro procedures on kinetics of oocyte maturation and embryo development. In Vitro Cell Developmental Biology Animal, v. 47, n. 5/6, p. 361-367, 2011.

18. KONISHI, M.; AOYAGI, Y.; TAKEDOMI, T.; ITAKURA, H.; LTOH, T.; YAZAWA, S. Presence of granulosa cells during oocyte maturation improved in vitro development of ivm-ivf bovine oocytes that were collected by ultrasound-guided transvaginal aspiration. Theriogenology, v. 45, n. 3, p. 573-581, 1996.

19.PARRISH, J. J.; SUSKO-PARRISH, J. L.; WINER, M. A.; FIRST, N. L. Capacitation of bovine sperm by heparin. Biology of reproduction, v. 38 , n. 1, p. 1171-1180, 1988

20.FERREIRA, E. M.; VIREQUE, A. A.; ADONA, P. R.; FERRIANI, R. A.; NAVARRO, P. A. Prematuration of bovine oocytes with butyrolactone I reversibly arrests meiosis without increasing meiotic abnormalities after in vitro maturation. European Journal of Obstetrics \& Gynecology and Reproductive Biology, v. 145, n. 1, p.76-80, 2009.

21.LONERGAN, P.; FAERGE, I.; HYTTEL, P. M.; BOLAND, M.; FAIR, T. Ultrastructural modifications in bovine oocytes maintained in meiotic arrest in vitro using Roscovitine or Butyrolactone. Molecular Reproduction and Development, v. 64, n. 3, p. 369-378, 2003.

22.DODE, M. A. N.; ADONA, P. R. Developmental capacity of Bos indicus oocytes after inhibition of meiotic resuption by 6-dimethylaminopurine. Animal Reproduction Science, v. 65 , n. 3/4, p. 171-180, 2001.

23. BARRETTO, L. S. S.; CAIADO CASTRO, V. S. D.; GARCIA, J. M.; MINGOTI, G. Z. Role of roscovitine and IBMX on kinetics of nuclear and cytoplasmic maturation of bovine oocytes in vitro. Animal Reproduction Science, v. 99, n. 1/2, p. 202-207, 2007.

24.ADONA, P. R.; PIRES, P. R. L.; QUETGLAS, M. D.; SCHWARZ, K. R. L.; LEAL, C. L. V. Nuclear maturation kinetics and in vitro embryo development of cattle oocytes prematured with butyrolactone I combined or not combined with roscovitine. Animal Reproduction Science, v. 104, n. 2/4, p. 389-397, 2008.

25.FAERGE, I.; MAYES, M.; HYTTEL, P.; SIRARD, M. A. Nuclear ultrastructure in bovine oocytes after inhibition of meiosis by chemical and biological inhibitors. Molecular Reproduction and Development, v. 59, n. 4, p. 459-467, 2001.

26. ALBARRACÍN, J. L.; MORATO, R.; IZQUIERDO, D.; MOGAS, T. Effects of roscovitine on the nuclear and cytoskeletal components of calf oocytes and their subsequent development. Theriogenology, v. 64, n. 8, p. 1740-1755, 2005.

27. BARRETTO, L. S. S.; CASTRO, V. S. D. C.; GARCIA, J. M.; MINGOTI, G. Z. Meiotic inhibition of bovine oocytes in medium supplemented with a serum replacer and hormones: effects on meiosis progression and developmental capacity. Zygote, v. 19, n. 2, p.107-116, 2010. 